\title{
O Debate sobre Dependência, Marginalidade e Informalidade: Para Uma Perspectiva de Abordagem do Fenômeno Sulanca
}

\section{The Debate about Dependency, Marginality and Informality: Towards a Perspective of Approach on the Sulanca Phenomenon}

\author{
Annahid Burnett \\ Doutoranda em Ciências Sociais da Universidade Federal de Campina Grande, PB \\ aburnett8@hotmail.com
}

\begin{abstract}
Resumo: O presente trabalho tem como objetivo apresentar uma explicação teórica para o fenômeno produtivo/comercial denominado Feira da Sulanca situado no Agreste de Pernambuco o qual começou a ser configurado nas décadas de 1950 e 1960. Para tal esforço lançamos mão das Teorias do desenvolvimento, dos enfoques na dependência e da marginalidade e da bibliografia especializada na informalidade. Temos como hipótese que o fenômeno sulanca se configurou a partir de uma massa marginal formada durante o segundo momento do capitalismo dependente, no período do fordismo periférico, sob forte relação com as práticas das feiras livres do Agreste pernambucano.
\end{abstract}

Palavras-chave: Desenvolvimento. Dependência. Marginalidade. Informalidade. Sulanca.

\begin{abstract}
This paper aims to explain theoretically the productive/commercial phenomenon called Feira da Sulanca situated in the Agreste region of Pernambuco state, northeast of Brazil, which began in the 1950s, 1960s. Such an effort used the Theories of development, the dependency and marginality approaches and the specialized bibliography in informality. Our hypothesis is that the phenomenon sulanca was formed from a marginal mass during the second moment of Brazilian dependent capitalism called peripheral fordism under strong relation to the popular practices of free markets in the northeast of Brazil.
\end{abstract}

Keywords: Development. Dependency. Marginality. Informality. Sulanca.

Originais recebidos em: 14/10/2013

Aceito para publicação em: 15/05/2014

\section{c) (1) $\$(9$}

Comercial-Vedada a criação de obras derivadas 3.0 Unported License. 


\section{Introdução}

Este artigo propõe um debate teórico sobre a instituição do aglomerado produtivo-comercial denominado de Feira da Sulanca no Agreste de Pernambuco, por meio de diálogo crítico com a bibliografia pertinente aos enfoques sobre desenvolvimento, marginalidade e informalidade.

Temos como hipótese que esse fenômeno produtivo-comercial se desenvolveu a partir do trabalho dos agricultores das pequenas propriedades denominadas de sítios, situados no Agreste de Pernambuco e pela massa marginal formada pelos retirantes integrantes do êxodo rural nordestino que se estabeleceu na década de 1950, na direção da região industrial de São Paulo, sob importante relação com a dinâmica socioeconômica da região do Agreste pernambucano, a tradicional prática das feiras livres. Temos como premissa que a instituição da Feira da Sulanca se configurou no cenário do segundo momento do capitalismo dependente, este com centro em São Paulo, o qual contou como exército industrial de reserva com a mão de obra dos retirantes nordestinos. Portanto, esta configuração comercial produtiva guarda relação com a massa marginal criada a partir da realidade daquele momento específico do fordismo periférico e dos espaços que não foi capaz de ocupar.

A Feira da Sulanca ${ }^{l}$ teve origem em Santa Cruz do Capibaribe situada na Mesorregião do Agreste pernambucano, a qual é uma região intermediária entre o Litoral/Mata de clima úmido e o Sertão semiárido e, mais especificamente na Microrregião do Alto Capibaribe, onde se situa a nascente do rio Capibaribe. Sendo uma região intermediária, a Mesorregião do Agreste é naturalmente bem diversificada, permeada de brejos de altitude, verdadeiros oásis que permitem a agricultura permanente, em meio a áreas de caatinga onde tradicionalmente se desenvolveu a pecuária extensiva para abastecer a região metropolitana, como observado por Manuel Correia de Andrade (2005). Geologicamente a Mesorregião do Agreste está situada no Planalto da Borborema em altitude média entre 400 a 800 metros, também conhecido como Serra das Ruças ${ }^{2}$, região montanhosa no interior do Nordeste brasileiro e se estende pelos estados da Paraíba, Pernambuco, Rio Grande do Norte e Alagoas (IBGE, 2011). O município de Santa Cruz do Capibaribe dista de $180 \mathrm{~km}$ da capital do estado,

\footnotetext{
${ }^{1} \mathrm{O}$ vocábulo Sulanca supostamente originou-se das palavras helanca, referindo-se aos retalhos de tecido sintético usado nos anos 1960, os quais vinham do Sul. Portanto, sul+helanca $=$ sulanca.

${ }^{2} \mathrm{O}$ IBGE adota a grafia tradicional, Ruças, que quer dizer névoa, neblina no português castiço.
} 
Recife, e faz parte de um território tradicionalmente denominado de Cariris Velhos, com baixa densidade pluviométrica e solos rasos.

O fenômeno produtivo/comercial denominado Feira da Sulanca emergiu durante as décadas de 1950 e 1960, a partir do aproveitamento dos retalhos provenientes da indústria têxtil do Recife num primeiro movimento, e dos retalhos vindos dos rejeitos da indústria têxtil vindos de São Paulo, num segundo movimento, os quais se adicionaram aos usados a priori. Esses retalhos serviam de matéria-prima para as costureiras dos sítios, as quais produziam peças de roupas e cobertas emendando os retalhos para serem vendidas nas feiras livres, servindo como complementação da renda do sítio. A mão de obra era a familiar, a unidade produtiva o domicílio e a produção doméstica e artesanal. Essa unidade produtiva passou para a zona urbana seguindo as exigências tecnológicas da linha de produção, uma vez que os retalhos vindos do Sul demandavam maior tecnologia dos meios de produção, e se tornou semi-industrial. Esse fenômeno se expandiu formando uma rede nacional de parentesco e amizade de arranjos produtivos e comerciais diferenciados e hoje é denominado de Polo de Confecções do Agreste de Pernambuco.

De acordo com pesquisadores que estudam as migrações dos "nordestinos"3, o Estado, depois da abolição da escravatura, incentivou a adoção da mão de obra imigrante desde o fim do século XIX. A priori, atraindo imigrantes estrangeiros para trabalhar nas fazendas de café e, a posteriori, os nordestinos para o campo e a indústria. Esses trabalhadores imigrantes eram alojados na Hospedaria dos Imigrantes, situada no bairro do Brás e, depois da triagem, eram deslocados para seu destino de trabalho. Essa realidade perdurou com sucesso durante a década de 1930 e 1940, na primeira fase do capitalismo dependente, com os contingentes de migrantes sendo destinados para a indústria leve e para o campo. Mas, essa prática mudou nas décadas de 1950 e 1960, na segunda fase do capitalismo dependente, quando o contingente de migrantes do campo para a cidade aumentou, com as grandes secas no Nordeste e a mecanização nas áreas agrícolas mais desenvolvidas, quando o mercado de trabalho nos grandes centros industriais já se mostrava saturado e os investimentos na indústria de bens duráveis demandavam mão de obra cada vez mais qualificada, como observado em Reale (1982), Albuquerque Jr. (1990), Andrade (1991) e Gomes (2006). Essa mudança no quadro

\footnotetext{
${ }^{3}$ Reducionismo aplicado aos imigrantes retirantes da seca atraídos pelo polo industrial centralizado em São Paulo, termo usado até hoje e que produziu uma imagem generalizante dos habitantes da região Nordeste.
} 
econômico e social na cidade e no campo foi gerando um excedente de força de trabalho, um exército industrial de reserva. Mas, mais do que isso, formou uma massa marginal, que teve que se reinventar na informalidade, para garantir sua reprodução social.

Dessa forma, essa mão de obra excedente que se alojava no bairro do Brás, antigo bairro industrial e operário de São Paulo, onde se localizam as indústrias e lojas de confecções, começou a catar os rejeitos das fábricas têxteis e inventar uma forma de comércio para sobreviver. É justamente nos "bastidores" das antigas indústrias têxteis que vão surgir os retalheiros, categoria verificada em Gomes (2006), se nutrindo das toneladas de resíduos de confecções e retalhos através de um comércio para as costureiras da Grande São Paulo e para as sacoleiras de todas as regiões do país. Porém, a maior parte desta mercadoria passou a ser levada para Santa Cruz do Capibaribe, para ser transformada em produtos, tais como: cobertas, vestidos, roupa infantil, feitas nos domicílios improvisadamente pela família nuclear, visando o comércio para uma população de baixa renda que comprava esses produtos nas feiras livres, o que se configurou no fenômeno comercial produtivo chamado Feira da Sulanca. Essa "transformação" estabeleceu uma interação comercial entre as duas regiões e a estruturação de redes de pessoas e produtos que passaram a depender desse comércio instituído à margem do mercado formalizado.

Nosso recorte de pesquisa se situa da década de 1950 até a década de 1980, pois a partir dos anos 1990, devido ao grandioso vulto tomado por este fenômeno produtivo comercial e, à disseminação global do ultraliberalismo ${ }^{4}$, através das práticas de empreendedorismo, alguns agentes exógenos públicos e privados ${ }^{5}$, iniciam uma campanha de sistematização e formalização, quando esse aglomerado passa a ser denominado de Polo de Confecções do Agreste de Pernambuco.

Por conseguinte, faremos um levantamento da bibliografia pertinente aos temas do desenvolvimento, elencando as diversas Teorias do desenvolvimento que floresceram na cena sociológica do pós-guerra, como também trabalharemos as obras relevantes aos termos marginalidade e informalidade. Não temos por objetivo aprofundar nenhuma das teorias historicamente situadas. Pretendemos, tão somente, estabelecer uma panorâmica temporal das teorias no âmbito do desenvolvimento, da

\footnotetext{
${ }^{4}$ Termo utilizado por analistas políticos europeus para designar a exacerbação do liberalismo a partir da era Thatcher/Reagan. Ver a respeito Todorov (2010).

${ }^{5}$ Com destaque para o SEBRAE. Ver a respeito Lima (2011).
} 
marginalidade e da informalidade, na intenção de construirmos um fio condutor estruturador do pensamento que irá nos situar dentro do nosso esforço de pesquisa.

\section{As Teorias do desenvolvimento e a questão da Dependência}

A Teoria do desenvolvimento é inspirada na linha de pensamento neoclássica de Alfred Marshall que explica o desenvolvimento e o subdesenvolvimento através de indicadores quantitativos. Dessa forma, consideram-se os lugares desenvolvidos ou "modernos" os com renda alta e os subdesenvolvidos ou "tradicionais" os que mostram baixa renda. Sendo assim, defende a ideia de que o capitalismo é responsável pelo desenvolvimento, mas não é a causa do subdesenvolvimento, portanto, é considerado um modelo tecnocrata neocolonialista. O Plano Marshall foi responsável pela reestruturação da Europa depois da Segunda Guerra Mundial, através da ajuda financeira dos Estados Unidos e da implantação do novo modelo e estilo de vida americanos. Época em que o Fordismo foi implantado e seguido como um novo regime de acumulação capitalista intensivo, centrado no crescimento do consumo de massa. Considerado por Lipietz (1989), como a segunda Revolução Industrial.

A Teoria da Modernização, desenvolvida por William Rostow (1956), se constituiu em uma das principais referências da política norte-americana para os países subdesenvolvidos. Essa sustentava que os países menos desenvolvidos iriam continuamente alcançar o mundo industrializado ao copiar o sistema econômico e social do capitalismo ocidental. Baseada amplamente nas premissas teóricas do funcionalismo estrutural, a Teoria da Modernização conceituou desenvolvimento como uma transição, em estágios, da tradição à modernidade, para acontecer em âmbito econômico através das operações de mercado e de investimento externo; no âmbito social, pela adoção dos comportamentos, valores e instituições ocidentais; e em âmbito político, pela implementação da democracia liberal.

Outro enfoque tentando explicar o desenvolvimento se afirmou com base nas chamadas teorias dualistas, que identificavam, em certos continentes, países ou regiões, uma formação peculiar, na qual coexistiriam duas estruturas distintas. Uma, desenvolvida, que apresentaria crescimento industrial, expansão urbana, sistema de comunicações amplo e diversificado, alta produtividade e avanço tecnológico. Outra, atrasada, na qual encontraríamos cidades com pequena área e população reduzida, 
produção eminentemente agrária, níveis de renda baixos, produtividade insuficiente e dispersão demográfica. Um autor dualista de relevância foi Jacques Lambert (1978) que, nos seus estudos sobre a América Latina, afirmou que o Brasil estava dividido em duas sociedades, uma "arcaica" e outra "moderna", as quais não haviam evoluído no mesmo ritmo e não haviam atingido a mesma fase.

Todavia, para outros autores, a coexistência entre o "tradicional" e o "moderno" seria o resultado de relações de dependência entre as sociedades periféricas e o capitalismo central. Andre Gunder Frank (1976), por exemplo, argumentou que a teoria dualística ou de sociedade dual, onde um mundo desenvolvido, moderno e capitalista convive, mas sem interagir, com um mundo arcaico e pré-capitalista, é falsa. Segundo Gunder Frank, o subdesenvolvimento não é o resultado de certo atraso temporal no desenvolvimento das forças produtivas. A expansão do sistema capitalista havia penetrado até mesmo nos setores mais isolados do mundo, de modo que o subdesenvolvimento seria resultado do desenvolvimento histórico do sistema capitalista, expressando um vínculo de dependência das metrópoles nacionais desses países subdesenvolvidos em relação às metrópoles internacionais. Sua Teoria do desenvolvimento do subdesenvolvimento propôs um sistema de metrópoles e satélites constituído na cadeia do sistema capitalista mundial colonial e nacional.

Essa teoria de Gunder Frank corroborava a Teoria do imperialismo e da colonização de Rosa Luxemburgo (1976), a qual argumentava que o mercado capitalista havia atingindo um subconsumo que provocava a expansão das fronteiras do capitalismo, levando à subjugação e ruína das comunidades tradicionais, causando destruição das relações de trocas primitivas, pilhagem de recursos naturais, transformação da população em compradores, resultando em acumulação e devastação. Mais tarde, a Teoria do imperialismo de Rosa Luxemburgo foi atualizada por David Harvey (2003), que a reelaborou como Teoria do Novo Imperialismo, já na fase do capitalismo por ele denominado de acumulação por espoliação. Ou seja, o que na época de Marx era o direito à propriedade privada através da espoliação da terra para criar um proletariado sem terra, se transformou em: expropriação de direitos de propriedade intelectual; em biopirataria; em espoliação dos recursos ambientais; em expropriação das terras comuns dos povos nativos; em perda dos direitos trabalhistas. Tudo isso para resolver o problema da sobreacumulação de excedente de capital que se apossa desses ativos para obter lucratividade, já na chamada Terceira Revolução Industrial, no fim do século XX. 
A despeito da acumulação capitalista, Lipietz (1989) sustenta que existem vários regimes de acumulação que podem ser classificados em extensivo e intensivo. Concebendo que a finalidade da acumulação capitalista é de aumentar a escala de produção ou reorganizar a divisão social do trabalho com o objetivo de obter maior produtividade e lucro, sustenta que a história do capitalismo passou por várias fases de acumulação. O autor denomina a fase que vai da Revolução Industrial até o período da Primeira Grande Guerra de Primeira Revolução Industrial, a qual se deu nos países centrais com base em um regime de acumulação extensiva, ou seja, baseado na reprodução de bens de capital, o chamado capitalismo concorrencial. Para ele, a Segunda Revolução Industrial se deu depois da Segunda Guerra Mundial, a partir da reprodução do fordismo como regime de acumulação intensiva, baseado no consumo de massa, denominado de capitalismo monopolista. Por conseguinte, baseados neste raciocínio, a Terceira Revolução Industrial se inicia no fim do século XX através da reestruturação produtiva e de um regime de acumulação flexível, ou como prefere chamar Harvey (2003), acumulação por espoliação.

Voltando à fase da então Segunda Revolução Industrial, no contexto fordista do pós-guerra, durante a reestruturação do mercado internacional e do desenvolvimento, foi criada a CEPAL - Comissão Econômica para a América Latina, que focalizou nas causas, condições e obstáculos ao desenvolvimento na América Latina. Seu principal representante foi Raul Prebisch, estudioso das relações entre o Centro e a Periferia, ou seja, desenvolvimento e subdesenvolvimento. Prebisch (1949) argumentava que as relações econômicas entre o Centro e a Periferia tendiam a reproduzir as condições do subdesenvolvimento e aumentar a distância entre os países desenvolvidos e subdesenvolvidos. Para ele, se desenvolvia um processo de apropriação da maior parte do progresso técnico pelos países centrais, resultante da deterioração dos termos de troca entre os bens primários e manufaturados. Portanto, de acordo com Cardoso (1993, p. 38), a tese cepalina de Prebisch "sustenta que o progresso técnico somado a condições sociais específicas produz consequências diferenciais entre o Centro e a Periferia".

Nesta perspectiva, Francisco de Oliveira (1987) argumentou que o subdesenvolvimento era precisamente uma produção da expansão do capitalismo e que as economias pré-industriais da América Latina foram criadas pela expansão do capitalismo mundial, como uma reserva de acumulação primitiva do sistema global. Em resumo: o subdesenvolvimento era uma formação capitalista e não simplesmente 
histórica. Na observação de Cardoso e Faletto (1970), apesar dos pressupostos favoráveis para uma nova etapa no desenvolvimento da América Latina, na década de 1950, tais como: a formação de um mercado interno e de uma base industrial, a formação de divisas e estímulos para o crescimento econômico, ou seja, às condições economicamente satisfatórias para passar da fase de substituição de importações para a produção autônoma, visando o mercado interno, esse fato não se confirmou. Ao contrário, houve uma estagnação relativa da economia brasileira nos anos de 1960. Baseando-se nessas premissas, os autores elaboraram a Teoria da Dependência, que pressupunha uma unidade dialética entre a dinâmica geral do capitalismo internacional e a dinâmica interna dos países dependentes, provocando uma reorganização da divisão internacional do trabalho. Essas situações de dependência refletiam o processo histórico da articulação capitalista das classes sociais periféricas com as economias centrais, através de condicionamentos sociais e políticos no processo de expansão do sistema capitalista internacional. As relações de dependência seriam dinâmicas históricas particulares, próprias de cada situação de dependência, situando o modo de produção capitalista através dos interesses locais, das classes, do Estado e dos recursos naturais, conforme afirmava Cardoso (1970). Dessa forma, a Teoria da Modernização foi deslocada, no fim dos anos 1960, por meio do enfoque da dependência.

\section{A emergência da Teoria da Marginalidade}

Também a partir de uma abordagem crítica sobre os resultados frustrantes das experiências desenvolvimentistas na América Latina e inspirando-se em uma perspectiva marxista, se desenvolveu a Teoria da Marginalidade. Um dos seus mais expressivos expoentes foi José Nun (2000), com sua Tese da Massa Marginal. O autor parte do pressuposto de que não se deve confundir as noções de superpopulação relativa e exército industrial de reserva, discutidas por Marx em Grundisse e O Capital. Para o referido autor, Marx teria tratado da ideia de exército de reserva como expressão da superpopulação relativa naquele momento do desenvolvimento capitalista, o que teria causado a confusão. O exército industrial de reserva foi analisado por Marx nas suas formas latente, estagnada (formas transicionais) e flutuante.

Sobre a produção crescente de uma superpopulação relativa ou de um exército industrial de reserva, Marx (1950) sustenta que a demanda de trabalho absoluta que 
ocasiona um capital se dá em razão não de sua grandeza absoluta, mas, de sua parte variável, que é representada pela força operária. A demanda de trabalho relativa que ocasiona um capital, ou seja, a proporção entre sua própria grandeza e a quantidade de trabalho que ele absorve, é determinada pela grandeza proporcional de sua fração variável. Portanto, a acumulação que amplia o capital social reduz simultaneamente a grandeza proporcional de sua parte variável e diminui dessa forma a demanda de trabalho relativa.

Sendo assim, retomando as categorias de Marx (1950), vemos que a indústria moderna não para de atrair e rejeitar alternadamente os operários. Portanto, o número de trabalhadores explorados vai aumentar como vai diminuir proporcionalmente à escala da produção, transformando uma superpopulação existente em sua forma flutuante. Dentro do sistema industrial moderno, onde as máquinas desempenham um papel auxiliar junto à divisão moderna do trabalho, a indústria emprega massivamente os operários jovens do gênero masculino. Dessa massa jovem, se aproveita um contingente baixo e se descarta a maioria. Este elemento da superpopulação aumenta à medida que a grande indústria se estende. Uma parte migra seguindo a migração do capital. Como a população feminina aumenta mais rápido do que a masculina e o crescimento natural da classe operária não é suficiente à necessidade de acumulação capitalista e ultrapassa, apesar disso, as faculdades de absorção do mercado nacional, essa situação vai conduzir a uma contradição, que é inerente ao movimento do capital, o qual necessita de uma proporção maior de mulheres, crianças e adolescentes, mais do que de homens feitos.

Marx (1950) observa que o regime capitalista se apropria da agricultura e que a demanda de trabalho no campo diminui absolutamente à medida que o capital se acumula. A repulsão da força de trabalho não é na agricultura, como na indústria, compensada por uma atração superior. Uma parte da população do campo se encontra sempre no ponto de se converter em população urbana ou manufatureira e à espera de circunstâncias favoráveis a esta conversão. Para que as zonas rurais se tornem uma fonte de migração para as cidades, é necessário que no próprio campo haja uma superpopulação latente a qual só é percebida quando os canais de descarga se escancaram. O trabalhador agrícola se encontra com o salário reduzido ao mínimo e já a um passo do pauperismo. Esta superpopulação latente de Marx já se encontrava no Nordeste agropastoril dos anos 1950 e as grandes secas daquela época criaram um êxodo rural ("os canais de descarga" de Marx), em direção a São Paulo onde se 
encontrava a indústria daquela época e a transformou numa massa marginal urbana de São Paulo, a qual instituiu o fenômeno da produção de sulanca.

Continuando com Marx (1950), a terceira categoria da superpopulação relativa, a estagnada, pertence bem ao exército industrial ativo, mas ao mesmo tempo a irregularidade extrema das suas ocupações faz dela um reservatório inesgotável de forças disponíveis. Acostumada à miséria crônica, às condições de existência precárias e vergonhosamente inferiores ao nível normal da classe operária, ela se torna a grande base de ramificações especiais de exploração onde o tempo de trabalho atinge seu máximo e a taxa de salário seu mínimo. O trabalho dito a domicílio é um exemplo bem típico, onde se enquadra a produção de sulanca. Esta camada da classe trabalhadora se recruta sem cessar entre os excedentes da grande indústria e da agricultura e, sobretudo, nas esferas de produção onde a profissão sucumbe frente à manufatura e frente à indústria mecânica. Fora os contingentes auxiliares que vão da mesma forma engrossar suas fileiras, esta categoria se autorreproduz numa escala progressiva. As mesmas causas que desenvolvem a força expansiva do capital levam a colocar em disponibilidade a força operária, a reserva industrial deve aumentar com a energia da riqueza. A grandeza relativa do exército industrial de reserva se amplia, então, junto com os limites da riqueza. Quanto mais este exército de reserva aumenta, comparativamente ao exército ativo de trabalho, mais aumenta a superpopulação consolidada, excedente de população. Esta é, segundo Marx, a lei absoluta e geral da acumulação capitalista. A ação desta lei, como qualquer outra, é naturalmente modificada por circunstâncias particulares.

Conforme Nun (2000) é muito importante considerar que a superpopulação relativa, dependendo das circunstâncias, produz efeitos não funcionais, introduzindo, assim, a categoria da massa marginal. Segundo argumenta, há diversos processos de acumulação que se superpõem e se combinam, gerando mecanismos que se pluralizam e variam de funcionalidade de efeitos, de acordo com o setor, ao conceber a superpopulação relativa. Dentro desta ótica, os sulanqueiros e retalheiros consistiriam em uma massa marginal, mas se ela é funcional ou não analisaremos mais adiante.

Seguindo também uma linha do pensamento marxista, Milton Santos (1978) discorda de Nun e argumenta que a formação do salário nas atividades modernas também coloca em risco a tese da massa marginal. As enormes possibilidades de trabalho da massa marginal pesam fortemente sobre o mercado de trabalho não intelectual no circuito moderno, tendo como efeito o rebaixamento dos salários. Implica, 
ao mesmo tempo, um aumento da taxa de lucro. Portanto, para Santos (1978), não se pode concordar com Nun, quando este afirma que a massa marginal contém um elemento afuncional ou disfuncional. Ao contrário, ela teria um papel preciso no funcionamento da fase atual do sistema capitalista, porque facilitaria a acumulação no centro e na periferia.

Já na análise de Cardoso (1993), a marginalidade é funcional ao desenvolvimento capitalista periférico. Em determinadas condições, o barateamento da abundância da mão de obra pode influenciar na acumulação. Porém, a expansão capitalista não só depende do exército de reserva, mas do custo da reposição da força de trabalho, da taxa de lucro, da competição entre os capitalistas, da tecnologia, entre outras coisas. Para que a marginalidade force o rebaixamento do custo de reposição, atribuídos aos exércitos de reserva, ao mínimo, é preciso que seja um movimento amplo, como também os custos devem depender da existência de uma produção de meios de vida feita à margem do sistema capitalista-industrial - uma produção para o consumo à margem do sistema. As populações marginais devem ser explicadas pela formação histórica do capitalismo na América Latina, dentro de suas características de distintos modos de produção subordinados ao capitalista.

Outros autores contribuíram com essa discussão, favorecendo por ângulos diversos as abordagens centradas na noção de marginalidade. Anibal Quijano (1966), por exemplo, propôs a distinção entre pequena burguesia marginal (constituída por aqueles que se tornam marginais em consequência da posição marginal de sua profissão no sistema econômico renovado: artesãos, pequenos produtores de serviços e pequenos comerciantes) e assalariado marginal (que compreende uma espécie de extensão do restante do proletariado industrial urbano). Ao abandonar as atividades da pequena burguesia marginal na cidade ou no campo, e não tendo ainda ingressado na força de trabalho demandada pela indústria, são obrigados a procurar ocupações de salários marginais. Consideramos que os sulanqueiros formam hoje uma pequena burguesia emergente de origem rural que detêm o poder político e econômico da região, a partir do grupo de pioneiros na produção de sulanca.

$\mathrm{Na}$ visão de Jaime Campos (1971), nunca houve uma marginalidade generalizada. O que existe são tipos que variam com as dimensões e os referenciais. $\mathrm{O}$ autor observa que o conceito de marginalidade teve desde sua origem uma carga de valor, ou seja, indivíduos dentro de uma situação considerada moralmente deplorável. Portanto, não existiria uma única definição de marginalidade, mas determinadas 
dimensões privilegiadas de acordo com os valores e interesse de cada observador. De acordo com Kowarick (1985), a marginalidade é uma categoria antiga já percebida pelos estudiosos na Idade Média como fenômeno transitório, quando os proletários potenciais se transformaram, não em reais trabalhadores, mas numa massa de indigentes. Portanto, inerente ao modo de produção capitalista são os mecanismos que originam a marginalidade, criando desempregados, subempregados para a formação do exército industrial de reserva. Todavia, no capitalismo dependente latino-americano, as formas tradicionais de produção, como as economias de subsistência do setor agrícola, o artesanato rural e a indústria a domicílio e, também, a criação de "novas" formas, fazem parte de um modo de produção claramente capitalista articuladas no processo de acumulação. Um subdesenvolvimento que gera uma superexcludência, por não ser capaz de integrar sua força de trabalho.

Nesta perspectiva, a pesquisa de Rabossi (2008), registra várias versões sobre as origens da sulanca. Segundo o pesquisador, a produção de sulanca começou em Santa Cruz do Capibaribe na década de 1950 com a confecção de colchas de retalhos. Esses retalhos e telas, no início, vinham do Recife, trazidos por comerciantes que vendiam seus produtos em Santa Cruz. Depois, com a expansão do sistema nacional de estradas e rodagens, os retalhos começaram a chegar de São Paulo, provenientes dos descartes da indústria têxtil e de confecções paulistanas. De acordo com o autor, os retalhos eram levados por caminhoneiros que retornavam depois de despachar sua carga e posteriormente por ônibus fretados por comerciantes denominados de sacoleiros. Observamos aqui que o resíduo virou mercadoria, deixou de ser descartado e doado e passou a ser comerciado.

A respeito da mercadoria, Marx (1950) afirma que a riqueza das sociedades capitalistas representa uma imensa acumulação de mercadorias. A mercadoria significa um objeto exterior, algo que por suas propriedades satisfaz algumas necessidades humanas de alguma forma, quer sejam de origem fisiológica ou do desejo, sua natureza não muda a essência, seja o apetite do corpo ou do espírito. A utilidade de um objeto faz dele um valor de uso. O que faz o valor natural de um objeto é a propriedade que ele tem de satisfazer as necessidades ou as conveniências da vida humana. Mas, esta utilidade determinada pelas propriedades do corpo da mercadoria, tal como o ferro, o diamante, é consequentemente um valor de uso e é o trabalho concreto do homem que determina as qualidades da sua utilidade. Quando é uma questão de valor de uso, subentendemos sempre uma quantidade determinada, como uma tonelada de ferro ou 
uma dúzia de relógios. Os valores de uso só se realizam no uso da consumação. Dentro da sociedade capitalista eles são ao mesmo tempo o sustento material do valor de troca. O valor de troca aparece primeiramente como uma relação quantitativa, como a proporção da qual os valores de uso de espécies diferentes se trocam um pelo outro. $\mathrm{O}$ valor consiste na relação de troca que se encontra nas coisas, entre uma medida de uma proporção e tal medida de outras, relação que muda constantemente com o tempo ou lugar. O valor de troca parece algo arbitrário e puramente relativo, intrínseco, que imana da mercadoria, parece mais um contrassenso. Uma vez que tiramos o valor de uso das mercadorias, só lhes resta uma qualidade, aquela do produto do trabalho. O tempo socialmente necessário à produção das mercadorias é o exigido em todo trabalho, executado com o grau médio de habilidade e de intensidade e dentro das condições que, em relação ao meio social são normais. É, portanto, a quantidade de trabalho ou o tempo de trabalho socialmente necessário, numa dada sociedade, à produção de um artigo, que se determina sua quantidade de valor. A quantidade de valor de uma mercadoria varia, então, em razão direta da quantidade e em razão inversa da força produtiva do trabalho que se realiza nele. Ou seja, quanto maior é a força produtiva do trabalho, menor é o tempo necessário à produção de um artigo e menor é a massa de trabalho cristalizada nele, menor é o seu valor. Inversamente, quanto menos força produtiva de trabalho, mais tempo socialmente é necessário à produção de um artigo, maior é o seu valor. Portanto, a substância do valor é o trabalho e a medida da sua quantidade de valor é a duração do trabalho, estabelecida socialmente. Para produzir mercadorias, deve-se produzir valor de uso, mas, valor de uso para os outros, valores de uso sociais. Nenhum objeto pode ter um valor se ele não for útil. Se ele é inútil, o trabalho nele contido é investido inutilmente e consequentemente não cria valor. Logo, os retalheiros e sulanqueiros encontraram um valor de uso social para o que era considerado descarte, resíduo, lixo, consequentemente, sem valor. Esse produto se transformou em mercadoria, sulanca, adquirindo, assim, valor de uso e valor de troca, para satisfazer as necessidades de uma massa marginal resultado da superexcludência peculiar ao nosso capitalismo dependente latino-americano, na fase considerada como fordismo periférico, dentro da dinâmica mais ampla de acumulação do capitalismo central e periférico.

Já Paul Singer (1974) preferiu denominar este fenômeno de Setor Autônomo da economia não desenvolvida, se referindo às iniciativas individuais compostas de: atividades rurais; comércio varejista; serviços; artesãos e indústria doméstica como 
costureiras, produzindo sulanca, alfaiates, ceramistas. Esse trabalho autônomo seria fruto da sub-remuneração dos meios de produção. Portanto, não estariam no cálculo da produção o valor do espaço doméstico para produzir, nem a mão de obra familiar para poder absorver a força de trabalho ociosa e concorrer no mercado capitalista. Por outro lado, Prandi (1978) atribui ao mesmo fenômeno a categoria de trabalhador por conta própria, o qual, dentro da divisão social do trabalho, conta somente com sua própria força de trabalho aliada à força de trabalho familiar, dispondo de pouco ou nenhum capital, de baixo nível de qualificação e de condições materiais precárias, características da produção de sulanca. $\mathrm{O}$ autor argumenta que o confronto entre os trabalhadores assalariados e os "por conta própria" deve ser entendido dentro de uma realidade estrutural e não de relações históricas entre as duas categorias. O trabalhador por conta própria teoricamente estaria excluído da estrutura da sociedade de classes, detendo-se em produzir um valor de consumo para ser incorporado ao capital, porque faz parte das categorias residuais, que de acordo com a teoria marxista estariam fadadas ao desaparecimento por serem historicamente anacrônicas, mas ao contrário dessa previsão teria sobrevivido, se enveredando e se mesclando ao modo de produção capitalista. Sendo assim, de que maneira, então, o trabalho por conta própria participa do quadro mais amplo de acumulação sob o domínio do capital? Para Prandi (1978), o trabalho autônomo se alimenta do excedente produzido pela produção capitalista que assegura a sobrevivência ao excedente do exército industrial de reserva, mantendo, assim, o processo de depressão real dos salários e impedindo o desemprego em massa. Ou seja, a produção capitalista desvia uma parte de excedente produzido pelo trabalho assalariado para manter uma parcela da população que não lhe interessa de imediato. Portanto, o trabalho autônomo seria a produção de bens e serviços de baixo rendimento para o capital e a garantia para anular um possível conflito de classes. Prandi se opõe à Teoria da Marginalidade, quando argumenta que a lógica geral está em produzir mercadoria barata para contribuir com o barateamento da força de trabalho (informalidade), incluindo assim o trabalho autônomo no processo de organização de vários setores da produção. Prandi conclui que o trabalho por conta própria tem um sentido estrutural, um elemento específico do processo de acumulação do capitalismo latino-americano, muito mais do que um trabalho marginal.

Por conseguinte, o termo marginalidade é uma concepção latino-americana, para definir a pobreza mais extrema e se constitui em si mesmo em uma categoria explicativa. Há autores que explicam o significado do termo conforme o funcionamento 
do sistema ou do processo de desenvolvimento que implica modificações estruturais. Nessa discussão, a marginalidade é entendida como algo dentro do sistema, um dos ingredientes do seu dinamismo, à medida que facilita a acumulação pelo baixo nível de salários e oferta abundante de mão de obra disponível no setor tradicional. O sistema pode ter uma taxa de crescimento elevada apesar de não incorporar uma boa parte da população aos benefícios daquele crescimento, aponta Hoffman (1980).

Houve uma discussão acirrada nas décadas de 1960 e 1970 entre os intelectuais da época sobre se essa massa marginal não seria simplesmente o exército industrial de reserva de Marx e se seria funcional ou não. Outra alegação, ou questão, era de que o exército industrial de reserva seria incorporado ao processo produtivo e a nossa massa marginal latino americana seria incapaz de ser absorvida pelo setor monopolista, mas, teria sua função na dinâmica do subdesenvolvimento periférico a partir do desenvolvimento global.

Outro campo de abordagens se deteve sobre tais segmentos não absorvidos, ou não completamente absorvidos, pelo desenvolvimento capitalista na sua periferia, sendo sob a referência das noções de setor informal e de informalidade as quais analisaremos doravante.

\section{A evolução histórica do termo informalidade}

Conforme Machado da Silva (1971), a marginalização foi tida como um tema complexo porque refletia as particularidades específicas do processo de desenvolvimento latino-americano. Machado, nas suas pesquisas nas favelas do Rio de Janeiro, identificou um mercado de trabalho bipolar, que ele denominou de mercado formal e mercado não-formalizado, que apesar de opostos, seriam ambos, altamente institucionalizados. Portanto, a dicotomia formal/informal estaria referida tão somente ao âmbito jurídico. A tipicidade do mercado não-formalizado seria o significado econômico das relações pessoais, que transforma o trabalhador em cliente de inúmeros patrões.

Nesse mesmo momento, Keith Hart (1973) se utilizou do termo informal e informalidade ao pesquisar as atividades econômicas do setor de baixa renda e o subproletariado em Gana, na África Ocidental da década de 1960. O autor observou, na sua pesquisa, que a inflação dos preços, os salários inadequados e uma mais-valia 
crescente no mercado de trabalho urbano, levaram as atividades de geração de renda do subproletariado a um alto grau de informalidade.

As tentativas para explicar a informalidade produziram, segundo Alexandre Barbosa (2011), quatro correntes de interpretação. São elas: a corrente de visão estruturalista, representada principalmente por Prebisch e Tokman; a de inspiração marxista, através da Teoria da Dependência e da Marginalidade; a corrente neoliberal, tendo como seu principal representante De Soto e; os autores considerados neomarxistas, como Castells e Portes. Porém, um marco nesse debate foi o trabalho intitulado Oportunidades de Renda Informal e Emprego Urbano em Gana, publicado pelo antropólogo social britânico, Keith Hart, no Jornal de Estudos Africanos Modernos, em 1973, fruto de extensa pesquisa desenvolvida durante a década de 1960, sobre um grupo étnico do norte de Gana, chamado Frafras, que havia migrado para as áreas urbanas do sul de Gana no oeste da África, antiga colônia britânica e com graves problemas socioeconômicos, realidade semelhante aos nordestinos na mesma época em São Paulo.

A partir dessa experiência de Hart nas principais áreas urbanas de Gana, a OIT empreendeu uma pesquisa no Quênia, país ao Leste da África, também antiga colônia britânica, que resultou num relatório reconhecendo o setor informal e dando início às primeiras políticas públicas de emprego voltadas para esses segmentos. Victor Tokman (1977, 2001), herdeiro das ideias estruturalistas cepalinas de Prebisch e representante do P.R.E.A.L.C. (Programa Regional do Emprego para a America Latina e Caribe), partiu do pressuposto de que o modelo de crescimento latino-americano repercutia sobre o funcionamento dos mercados urbanos de trabalho. A incapacidade dos setores modernos de absorver a mão de obra num ritmo satisfatório, além da heterogeneidade da estrutura produtiva, determinava a existência de mercados de trabalho diferenciados. Os novos integrantes da força de trabalho urbano (provenientes do crescimento vegetativo das grandes cidades e das migrações rurais), não conseguiam emprego no setor moderno, tendo, então, que buscar trabalho em outros estratos produtivos.

Outro corte analítico bem latino-americano se estabeleceu sob uma perspectiva de tipo mais marxista, desenvolvida nas décadas de 1960 e 1970, abordada anteriormente e relacionada às Teorias da Dependência e da Marginalidade. O problema da marginalidade, para tal campo de estudos, se concentrou principalmente na capacidade de absorção da mão de obra pelo setor moderno e seus efeitos criadores de uma massa marginal, nos termos de Nun (2000), ou de polo marginal, nos termos de 
Quijano (2003), resultante do processo de acumulação de capital. Vimos que outros autores também trataram dessa questão, por ângulos diversos, tais como: Cardoso e Faletto (1970); Milton Santos (1978); Francisco de Oliveira 2003; Jaime Campos (1971); Helga Hoffman (1980); Lucio Kowarick (1985).

Quanto ao enfoque neoliberal, temos em De Soto (1986) seu maior expoente. A Teoria da Economia Subterrânea de De Soto propôs, a partir de um estudo minucioso junto aos que a exerciam em seu país, o Peru, que o setor informal não deveria ser visto mais como uma mera estratégia de sobrevivência, passível de ser descartada em um futuro remoto, mas como um caminho alternativo a ser trilhado pelas economias subdesenvolvidas. Para De Soto o setor informal seria a saída espontânea e criativa, encontrada principalmente pelas camadas populares, face à incapacidade do Estado em satisfazer suas aspirações mais elementares. Consequentemente, a "opção" pela ilegalidade em seus negócios e ocupações constituiria a única possibilidade às classes de renda mais baixas. De Soto apontou o Estado como sendo inoperante, incapaz e elitista e que marginalizava grande parte da população, além de ser burocratizado e não representativo da maioria. O excesso de burocracia do aparato estatal obrigava os desprivilegiados a procurarem a informalidade.

Outro enfoque mais recente sobre a informalidade é o da descentralização produtiva de Portes; Castells e Benton (1989), que remete à globalização e às mudanças ocorridas na divisão internacional do trabalho. Esta análise aborda o processo de adaptação das empresas modernas para enfrentar a competitividade do mercado mundial, o que estaria resultando na introdução de sistemas de produção flexíveis. Tratar-se-ia de descentralizar os processos de produção e de trabalho, de modo a reduzir os custos com a produção e a mão de obra, deslocando-os para o exterior da empresa. A descentralização se associa à subcontratação de produtos e de mão de obra objetivando a evasão de obrigações de encargos trabalhistas. Esses esquemas de terceirização estariam levando a um tipo de informalização, porém, desta feita, não mais visando à sobrevivência de uma ampla parcela marginalizada da população, mas, a sobrevivência da empresa para facilitar um maior poder de acumulação. De acordo com Tokman (2001), devemos distinguir os fatores que determinam a criação de postos de trabalho informais, do grau de inserção do resto da atividade econômica. Nem toda atividade gerada pela necessidade de sobrevivência é marginal ou está desconectada do resto do sistema. Essas atividades que surgem como resultado da descentralização, seriam, na verdade, funcionais às grandes empresas. 


\section{Considerações finais}

Dessa forma, as abordagens que se estabeleceram especialmente na segunda metade do século XX, sobre os processos de industrialização de sociedades dependentes, como a brasileira, e tendo como focos o desenvolvimento, a marginalidade e a informalidade, são de crucial importância ao estudo do fenômeno sulanca. Sobretudo, chamam a atenção para a importância de um segmento da economia e da população, nomeado diversamente como: massa marginal, polo marginal, setor informal, subemprego, circuito inferior da economia, trabalhador por conta própria, entre outras denominações. Quanto ao modo de interpretar tal fenômeno, evidencia na sua diversidade de pontos de vista, um duplo movimento: de um lado, o caráter diferenciado de sua dinâmica, quando em comparação com a lógica própria da acumulação capitalista; de outro, tais segmentos se constituem sob formas e graus diversos de imbricações com a dinâmica capitalista. Segundo Nun (2000), como vimos, diversos processos de acumulação se combinam, tendo como correspondente a pluralização dos mecanismos de geração da superpopulação relativa e as formas de funcionalidade de seus efeitos sobre a dinâmica capitalista. Ou seja, sua tese implica na possibilidade de existência de segmentos que se colocam funcionalmente ao processo de acumulação de capital (exército industrial de reserva) ao lado de outros que se colocam como irrelevantes para o setor hegemônico da economia (capitalista), sendo afuncionais em relação a esse. É nesse registro que pretendemos abordar a experiência de constituição do fenômeno produtivo-comercial no Agreste de Pernambuco. Ou seja, entre, de um lado, o que nele esteve presente como elementos mais diretamente derivados do processo de industrialização do país (a exemplo do papel exercido nessa formação pelos retalheiros) - funcionais - e, do outro, o que também teve importância central como constituição de uma dinâmica socioeconômica com características especiais (a exemplo do papel exercido nessa formação pelas feiras livres).

Considerando, portanto, toda esta argumentação teórica e contexto histórico no qual se instituiu o fenômeno produtivo comercial Feira da Sulanca, nós verificamos que tanto os retalheiros como os sulanqueiros são resultado de uma mesma massa marginal criada a partir da realidade econômico-social dos anos 1950 e 1960, fazendo parte do movimento mais amplo de acumulação do capitalismo mundial, porém fruto da nossa 
realidade latino-americana, e, assim sendo, com funcionalidades específicas ao nosso processo de acumulação dentro do período do fordismo periférico. Ou seja, o processo de acumulação do nosso capitalismo dependente latino-americano gerou um polo marginal, apresentando instabilidade, recursos residuais, rendas reduzidas, características do setor informal, que evoluiu com o tempo em arranjos diferenciados dando lugar ao que hoje denominaram de Polo de Confecções do Agreste de Pernambuco.

\section{Bibliografia}

ALBUQUERQUE JR., D. M. Paraíbas e Bahianos: órfãos do campo, filhos legítimos da cidade. In: Travessia, São Paulo: Centro de Estudos Migratórios. São Paulo, n.8, p. 2732, set/dez 1990.

ANDRADE, M. M. de. Bairros Além-Tamanduateí: o imigrante e a fábrica no Brás, Moóca e Belenzinho (Tese de doutorado em Geografia) - Departamento de Geografia da FFLCH, São Paulo: USP, 1991.

ANDRADE, Manuel Correia de. A terra e o homem no Nordeste - Contribuição ao estudo da questão agrária no Nordeste. São Paulo: Cortez, 2005.

BARBOSA, Alexandre de Freitas. O Conceito de Trabalho Informal, sua evolução histórica e o potencial analítico atual: para não jogar a criança fora junto com a água do banho. In: Marchas e contramarchas da informalidade do trabalho: das origens às novas abordagens / org. Roberto Véras de Oliveira; Darcilene Gomes; Ivan Targino. Editora Universitária: João Pessoa, PB, 2011.

CAMPOS, Jaime. El concepto de Marginalidad Social en América Latina. INTAL, 1971.

CARDOSO, F. H.; FALETTO, E. Dependência e Desenvolvimento na América Latina - Ensaio de Interpretação Sociológica. Zahar Editores: Rio de janeiro, 1970.

CARDOSO, Fernando Henrique. "Teoria da Dependência" ou Análises Concretas de Situações de Dependência? Texto apresentado no $2^{\circ}$ Seminário Latino-americano para El Desarrollo (promovido pela FLASCO, sob o patrocínio da UNESCO em novembro de 1970, Santiago, Chile) para comentar a comunicação de P. C. Weffort, "Notas sobre a teoria de classe ou ideologia nacional?" 1970. 
CARDOSO, Fernando Henrique. As ideias e seu lugar - Ensaios sobre as teorias do desenvolvimento. Vozes: Petrópolis, 1993.

DE SOTO, Hernando. Economia subterrânea: uma análise da realidade peruana. Editora Globo: Rio de Janeiro, 1986.

GOMES, Sueli de Castro. Uma inserção dos migrantes nordestinos em São Paulo: o comércio de retalhos. Imaginário, USP, 2006, vol 12, nº 13. 143-169.

GUNDER FRANK, Andre. America Latina: subdesarrollo o revolucion. Ediciones Era: México, 1976.

HART, Keith. Informal Income Oportunities and urban Employment in Ghana. The Journal of Modern African Studies, Volume II, Number I, março, 1973.

HARVEY, David. O Novo Imperialismo. Tradução Adail Sobral e Maria Stela Gonçalves. Edições Loyola: São Paulo, 2003.

HOFFMAN, Helga. Desemprego e Subemprego no Brasil. $2^{a}$ ed. Ática: São Paulo, 1980.

KOWARICK, Lúcio. Capitalismo e Marginalidade na América Latina. $4^{a}$ edição. Paz e Terra: Rio de Janeiro, 1985.

LAMBERT, Jacques. Os dois Brasis. Editora Nacional: São Paulo, 1978.

LIMA, Alexandre Santos. "Empreendendo" a Sulanca: O SEBRAE e o Polo de Confecções do Agreste de Pernambuco. Dissertação de mestrado no Programa de Pós-graduação em Ciências Sociais. Universidade Federal de Campina Grande, Paraíba, 2011.

LIPIETZ, Alain. Fordismo, Fordismo Periférico e Metropolização. Ensaios FEE, Porto Alegre, 10(2):303-335, 1989.

LUXEMBURGO, Rosa; BUKARINE, Nikolai. Imperialismo e acumulação de capital. Edições 70: Lisboa, 1976. 
MACHADO DA SILVA, Luís Antonio. Mercados Metropolitanos de Trabalho

Manual. Mestrado em Programa de pós-graduação em Antropologia Social.

Universidade Federal do RJ, Museu Nacional, 1971.

MARX, Karl. Le Capital - Critique de L'Économie Politique, Livre Premier, Le Dévelopment de La production Capitaliste, Tome Premier: La Marchandise et La Monnaie; Tome deuxième: La Production de La Plus-Value Relative, Nouvelle Recherches Sur La Production de La Plus-Value et Tome troisième: L'Accumulation Du Capital, L'Accumulation Primitive, Le Procès d'ensemble de la Production Capitaliste. Traduction de Joseph Roy et entièrement revisée par l'auteur. Éditions Sociales: Paris, 1950.

NUN, José. O Futuro do Emprego e a Tese da Massa Marginal. Revista de Ciências Sociales $n^{\circ}$ 152, vol. 38, 1999 e Latin American Perspectives 27(1), jan 2000. Tradução do espanhol de Alexandre Morales.

OLIVEIRA, Francisco de. A Economia Brasileira: Crítica à Razão Dualística. Editora Vozes: Petrópolis, RJ, 1987.

PORTES, A.; CASTELLS, M.; BENTON, L. The informal economy. Studies in advanced and less developed countries. Johns Hopkins University: Baltimore, 1989.

PRANDI, José Reginaldo. O Trabalhador por conta própria sob o Capital. Edições Símbolo: São Paulo, 1978.

PREBISCH, Raul. O Desenvolvimento Econômico da América Latina e seus Principais problemas. Revista Brasileira de Economia: América do Norte, 1949. Disponível em HTTP: // bibliotecdigital.fgv.br/ojs/índex.php/rbe/article/view/2443/1767. Acesso em 21 de abril de 2011.

QUIJANO, Anibal. Notas sobre El concepto de marginalidad social. División de Assuntos Sociales, CEPAL, Chile, 1966.

RABOSSI, Fernando. Em La Ruta de las Confecciones. Revista latinoamericana de ciencias sociales, dossier la vida social de la economia, Crítica em dessarrollo, $\mathrm{n}^{\mathrm{o}} 2$ segundo semestre, 2008.

REALE, E. B. Pinheiros, Jardins - Três bairros, três mundos. São Paulo: Edusp, 1982. 
ROSTOW, W. W. The take-off into self-sustained growth in: The Economic Journal, março, 1956.

SANTOS, Milton. Pobreza Urbana. Editora Hucitec: São Paulo, Recife, 1978.

SINGER, Paul. Elementos para uma teoria do emprego aplicável a países não desenvolvidos. CEBRAP/Brasiliense: São Paulo, 1974, Cadernos, nº 18.

TODOROV, Tzvetan. O medo dos bárbaros. Petrópolis: Vozes, 2010.

TOKMAN, Victor. Dinâmica Del Mercado de Trabajo Urbano: El Sector Informal Urbano en America Latina. OIT - Organizacion Internacional Del Trabajo /

P.R.E.A.L.C. - Programa Regional Del Empleo para America Latina e Caribe. Tercera Version, Junio de 1977.

TOKMAN, Victor. De la informalidad a la modernidad. Oficina Internacional del Trabajo: Santiago, Chile, 2001. 